\title{
ANALISIS KUAT TEKAN BETON MUTU TINGGI DENGAN BAHAN TAMBAH SUPERPLASTISIZER DAN LIMBAH LAS KARBIT
}

\author{
Hakas Prayuda $^{* 1}$ dan As'at Pujianto ${ }^{2}$ \\ ${ }^{1}$ Program Studi Teknik Sipil / Fakultas Teknik / Universitas Muhammadiyah \\ Yogyakarta \\ ${ }^{2}$ Program Studi Teknik Sipil / Fakultas Teknik / Universitas Muhammadiyah \\ Yogyakarta \\ Korespondensi: hakasprayuda@umy.ac.id
}

\begin{abstract}
This research will discuss about the compressive strength of concrete by using superplastisizer as an addictive substance and waste of carbide weld as the admixture material of cement replacement. Through this research is expected to know the right composition to produce a concrete formula with high quality by utilizing the existing local waste dan superplastisizer (Viscocrete-10). In this study made a sample of concrete cylinders measuring $15 \mathrm{~cm}$ diameter with a height of $30 \mathrm{~cm}$ totaling 63 specimens with 7 variations with each variation made as many as 9 specimens. The compressive strength test was performed at age 7, 14 and 28 days. Through this research, the result of flowability, compressive strength and elastic modulus of each test object variation.
\end{abstract}

Keyword: high strength concrete, local waste, carbide, elastic Modulus, compressive strength

\section{PENDAHULUAN}

Beton juga menjadi salah satu pilihan bahan struktur yang digunakan sebagai bahan konstruksi pada bidang struktur seperti gedung, jembatan, jalan, dan sebagainya. Dimana diperlukan beton mutu tinggi untuk memenuhi kebutuhan bangunan bertingkat tinggi dan jembatan berbentang panjang. Beton mutu tinggi (High Strength Concrete) [1] merupakan beton yang mempunyai kuat tekan lebih besar sama dengan 41.4 MPa. Peningkatan mutu beton dapat dilakukan dengan cara memberikan bahan tambah atau bahan ganti pada campuran beton, salah satunya dengan limbah las karbit. Limbah las karbit ini merupakan limbah hasil dari pengelasan.

Untuk mendapatkan beton dengan mutu tinggi, salah satu faktor yang berpengaruh adalah gradasi agregat kasar. Apabila gradasi agregat mempunyai ukuran yang lebih kecil dan lebih bervariasi ukurannya, maka pori pada beton menjadi kecil. Hal ini disebabkan oleh butiran yang lebih kecil akan mengisi lubang/rongga yang terdapat diantara agregat yang ukurannya lebih besar.
Faktor air semen adalah perbandingan antara air dan semen dalam campuran beton. Beton dengan faktor air semen yang tinggi akan menghasilkan beton dengan workabilitas yang tinggi tetapi kualitas beton rendah. Sebaliknya, beton dengan faktor air semen yang rendah akan menghasilkan beton yang lebih kuat. Akan tetapi beton dengan faktor air semen rendah akan menghasilkan campuran beton dengan workabilitas / kemudahan pengerjaan yang rendah. Oleh karena itu diperlukan penambahan superplasticizer untuk mempermudah pengerjaan beton dengan faktor air semen yang rendah. Tujuan dari penelitian ini adalah untuk kuat tekan beton tinggi dengan ukuran agregat dan kadar bahan tambah yang optimum.

Beberapa penelitian terdahulu mengenai beton mutu tinggi sudah dilakukan di antaranya pemanfaatan fly ash sebagai bahan tambah [2], Abu Sekam Padi [3], penambahan serat [4], menggunakan metakaolin dan hybrid fiber [5], menggunakan agregat recycle [6], menggunakan sistem geopolimer [7]. Selain itu terdapat pula beberapa penelitian yang 
menggunakan metode yang berbeda seperti menggunakan prediksi analisis regresi [8], model algoritma [9] dan metode maturity [10]. Diharapakn penelitian menggunakan abu limbah las karbit ini dapat menjadi material baru yang ramah lingkungan dalam pembuatan beton mutu tinggi.

\section{METODOLOGI PENELITIAN}

\subsection{Materi Penelitian}

Penelitian ini dilakukan di Labotarotium Teknologi Bahan Jurusan Teknik Sipil, Universitas Muhammadiyah Yogyakarta. Pada penelitian ini menganalisis kuat tekan beton pada umur 7, 14 dan 28 hari sebanyak 7 variasi dengan total sampel 63 benda uji dengan ukuran diameter $15 \mathrm{~cm}$ dan tinggi $30 \mathrm{~cm}$.

Variasi yang dianalisis melalui penelitian ini berupa ukuran agregat, variasi faktor air semen dan persentase limbah karbit yang digunakan. Adapun variasi benda uji dapat dilihat pada Tabel 1.

Tabel 1. Variasi campuran yang di teliti

\begin{tabular}{cccc}
\hline $\begin{array}{c}\text { Benda } \\
\text { Uji }\end{array}$ & FAS & $\begin{array}{c}\text { Kadar Variasi } \\
\text { Ukuran Agregat } \\
\text { Kasar }(\mathrm{mm})\end{array}$ & $\begin{array}{c}\text { Limbah } \\
\text { Karbit }(\%)\end{array}$ \\
\hline BT-1 & 0.28 & 10 & 10 \\
BT-2 & 0.28 & 15 & 10 \\
BT-3 & 0.28 & 20 & 10 \\
BT-4 & 0.24 & 10 & 10 \\
BT-5 & 0.32 & 10 & 10 \\
BT-6 & 0.28 & 10 & 5 \\
BT-7 & 0.28 & 10 & 15 \\
\hline
\end{tabular}

Melalui penelitian ini akan dihasilkan nilai slump pada masing-masing benda uji yang menunjukkan flowability dari seluruh sampel dengan kadar superplastisizer yang sama, kemudian memperoleh hubungan umur beton dengan kuat tekan beton sehingga dapat diketahui pengaruh umur terhadap kuat tekan beton.

\subsection{Bahan Penelitian}

Adapun bahan yang digunakan dalam penelitian ini adalah sebagai berikut.

a. Agregat halus yang digunakan adalah pasir Merapi, Sleman, Yogyakarta.

b. Agregat kasar yang digunakan adalah kerikil/split Clereng, Kulon Progo, Yogyakarta.

c. Semen yang digunakan dalam penelitian ini adalah semen PCC (Portland Cement Composit) merk Tiga Roda.

d. Air bersih yang digunakan dalam penelitian ini diambil dari Laboratorium Teknologi Bahan Konstruksi, Program Studi Teknik Sipil, Fakultas Teknik, Universitas Muhammadiyah Yogyakarta.

e. Bahan tambah kimia (superplasticizer) yang digunakan dalam penelitian ini adalah produk Viscocrete-10 dari PT. SIKA INDONESIA.

f. Limbah las karbit yang diambil dari PT. INDO HANZEL.

\subsection{Mix Design}

Perancangan mix design pada penelitian ini menggunakan metode dari [11] yang diperoleh hasil seperti pada Tabel 2 untuk kebutuhan $1 \mathrm{~m}^{3}$. Penggunaan superplastisizer dan limbah las karbit diambil dari persentase berat semen.

Tabel 2. Kebutuhan bahan penelitian

\begin{tabular}{ccccccc}
\hline Benda & \multicolumn{5}{c}{ Kebutuhan Material $($ Kg) dalam 1m3 } \\
Uji & Air & Semen & Kerikil & Pasir & SP & LLK \\
\hline BT-1 & 221.205 & 780.723 & 923.316 & 383.44 & 13.012 & 86.747 \\
BT-2 & 221.205 & 780.723 & 923.316 & 383.44 & 13.012 & 86.747 \\
BT-3 & 221.205 & 780.723 & 923.316 & 383.44 & 13.012 & 86.747 \\
BT-4 & 189.538 & 780.723 & 923.316 & 383.44 & 13.012 & 86.747 \\
BT-5 & 242.890 & 780.723 & 923.316 & 383.44 & 13.012 & 86.747 \\
BT-6 & 221.205 & 780.723 & 923.316 & 383.44 & 13.012 & 43.374 \\
BT-7 & 221.205 & 780.723 & 923.316 & 383.44 & 13.012 & 130.120 \\
\hline
\end{tabular}




\section{HASIL DAN PEMBAHASAN}

\subsection{Hasil Pemeriksaan Agregat}

Sebelum dibuat benda uji, agregat kasar dan halus terlebih dahulu dilakukan pemeriksaan seperti berat jenis, kadar lumpur , kadar air dan sebagainya. Adapun hasil pemeriksaan agregat halus dapat dilihat pada Tabel 3.

Dari tabel 3 dapat disimpulkan bahwa seluruh pengujian menunjukan bahwa pasir Merapi memenuhi persyaratan sebagai material pembuatan beton mutu tinggi. sedangkan hasil uji gradasi saringan dapat dilihat pada Gambar 1.

Tabel 3. Hasil pemeriksaan pasir Merapi

\begin{tabular}{lcc}
\hline \multicolumn{1}{c}{$\begin{array}{c}\text { Jenis Pengujian } \\
\text { Agregat }\end{array}$} & Satuan & Hasil \\
\hline Gradasi Butiran & - & 3 \\
Modulus Halus Butir & - & 3.06 \\
Kadar Air & $\%$ & 1.81 \\
Berat jenis & - & 2.52 \\
Penyerapan Air & $\%$ & 4.02 \\
Berat Satuan & $\mathrm{gram} / \mathrm{cm}^{3}$ & 1.65 \\
Kadar Lumpur & $\%$ & 5.64 \\
\hline
\end{tabular}

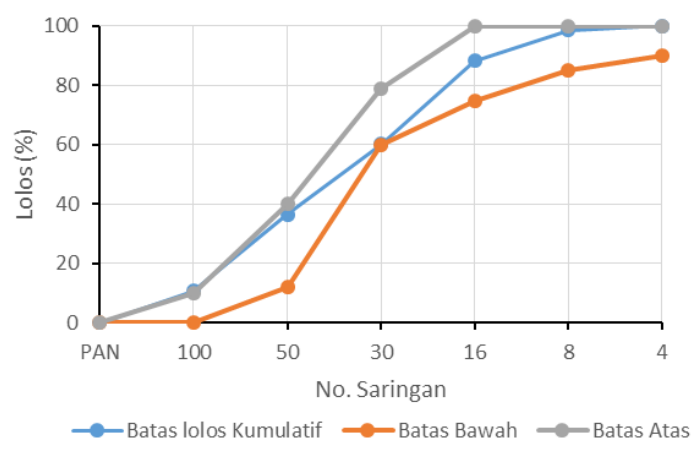

Gambar 1. Hasil uji gradari agregat halus
Tabel 4 menunjukkan hasil pengujian agregat kasar yang terdisi dari kadar air, kadar lumpur dan uji kausan beserta beberapa pengujian penting lainnya. Melalui pengujian ini agregat kasar Clereng disimpulkan memenuhi syarat dalam pembuatan beton.

Tabel 4. Hasil pemeriksaan kerikil Clereng

\begin{tabular}{lcc}
\hline \multicolumn{1}{c}{$\begin{array}{c}\text { Jenis Pengujian } \\
\text { Agregat }\end{array}$} & Satuan & Hasil \\
\hline Kadar Air & $\%$ & 2.73 \\
Berat Jenis & - & 2.71 \\
Penyerapan Air & $\%$ & 6.72 \\
Berat Satuan & $\mathrm{gram} / \mathrm{cm}^{3}$ & 1.43 \\
Kadar Lumpur & $\%$ & 2.52 \\
Keausan & $\%$ & 38.31 \\
\hline
\end{tabular}

\subsection{Hasil Pemeriksaan Slump}

Pemeriksaan nilai slump dilakukan untuk mengetahui nilai workability dari beton yang dibuat. Tabel 5 dan Gambar 2 menunjukkan hasil nilai slump yang diperoleh.

Hasil nilai slump terkecil diperoleh oleh sampel BT-4 sebesar $5 \mathrm{~cm}$ hal ini dikarenakn pengaruh dari nilai fas yang digunakan sangat kecil yaitu 0.24.

Tabel 5. Hasil pemeriksaan nilai slump

\begin{tabular}{cc} 
Benda Uji & Nilai Slump $(\mathrm{cm})$ \\
\hline BT-1 & 27.00 \\
BT-2 & 23.67 \\
BT-3 & 10.50 \\
BT-4 & 5.00 \\
BT-5 & 26.00 \\
BT-6 & 22.00 \\
BT-7 & 25.00 \\
\hline
\end{tabular}




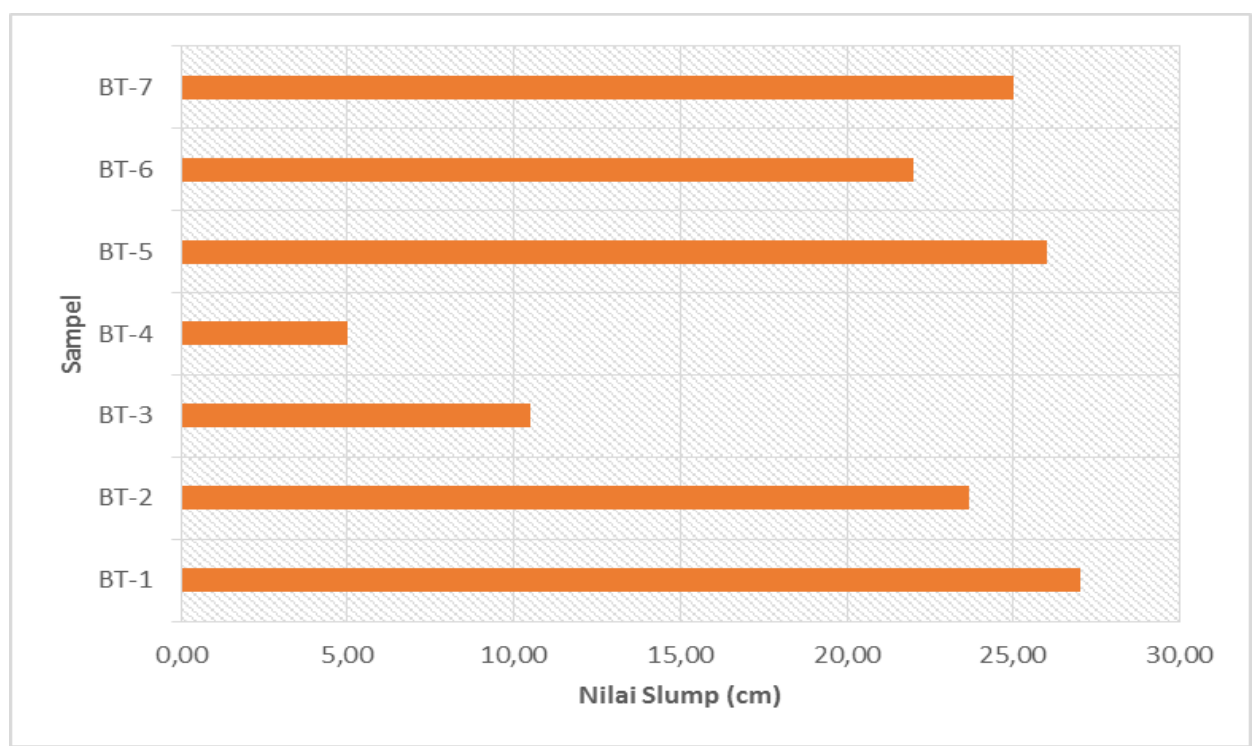

Gambar 2. Hasil pengujian nilai slump

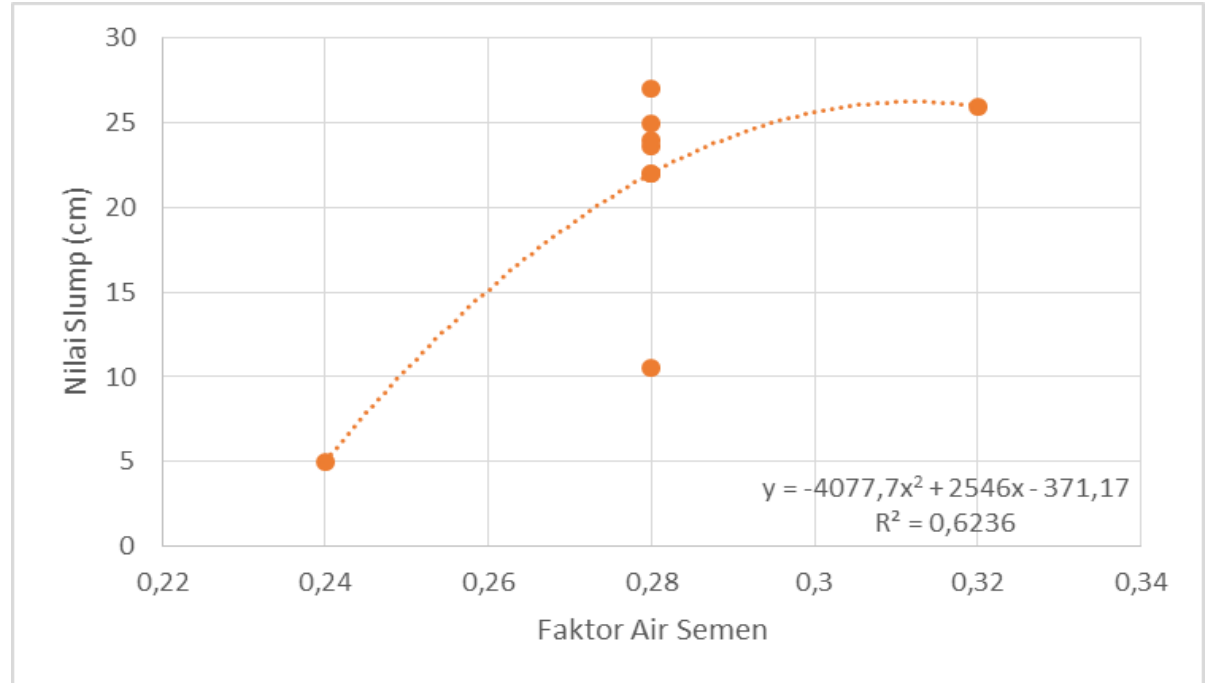

Gambar 3. Hubungan Faktor air semen dengan nilai slump

Gambar 3 menjelaskan hubungan nilai slump dengan faktor air semen dengan pembuatan beton menggunakan bahan tambah limbah las karbit. Semakin bertambahnya nilai fas akan bertambah tinggi juga nilai slump yang di hasilkan.

\subsection{Hasil Pemeriksaan Kuat Tekan}

Pengujian kuat tekan dilakukan pada umur 7,14 dan 28 hari. Adapun hasil pengujian kuat tekan dapat dilihat pada Gambar 4. Hasil yang depoleh menunjukkan bahwa kuat tekan tertinggi terdapat pada benda uji BT-2 memiliki kuat tekan tertinggi pada umur 28 hari yaitu sebesar 57.44 MPa. Benda uji BT-2 menggunakan variasi fas 0.28 dengan ukuran agregat maksimum $15 \mathrm{~mm}$ dan komposisi limbah las karbis sebesar 10\%. Sedangkan benda uji dengan kuat tekan terkecil pada benda uji BT-5 sebesar 29.33 MPa dengan variasi fas 0.32 , ukuran agregat maksimum 10 mm dan kadar limbah las karbit sebesar $10 \%$. 


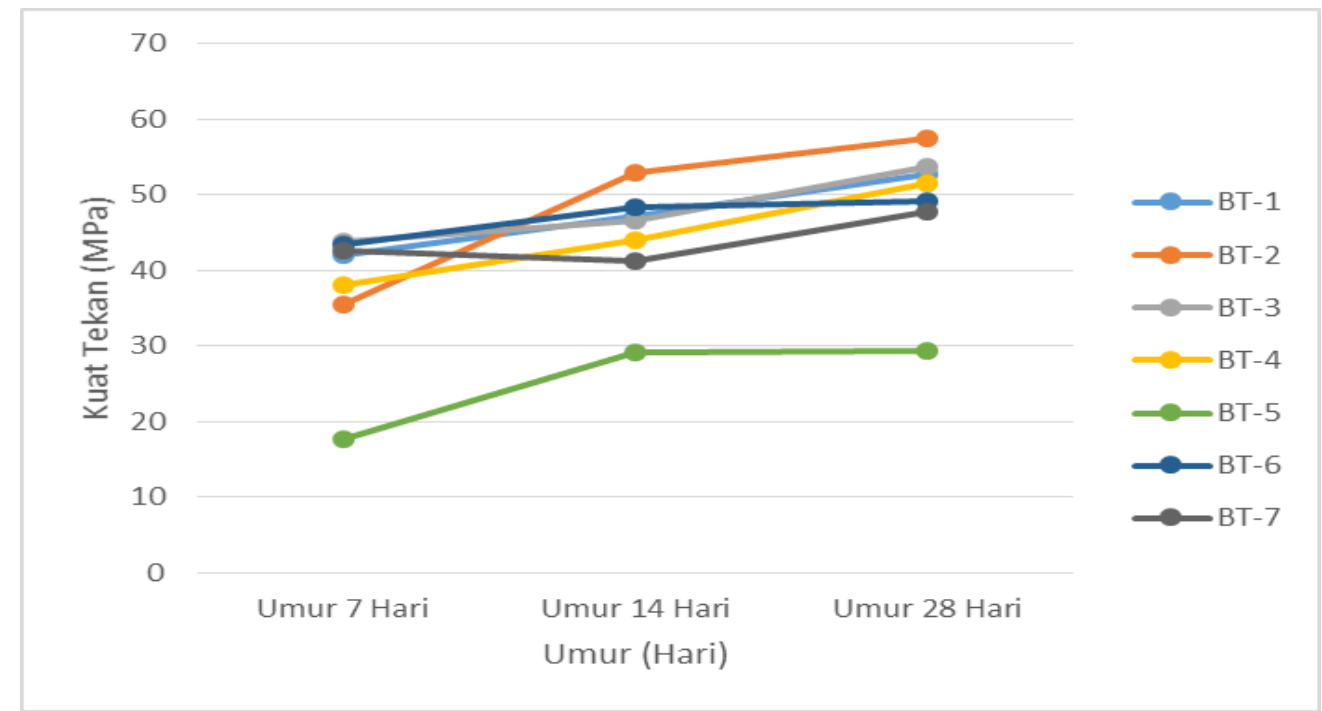

Gambar 4. Hasil pengujian kuat tekan

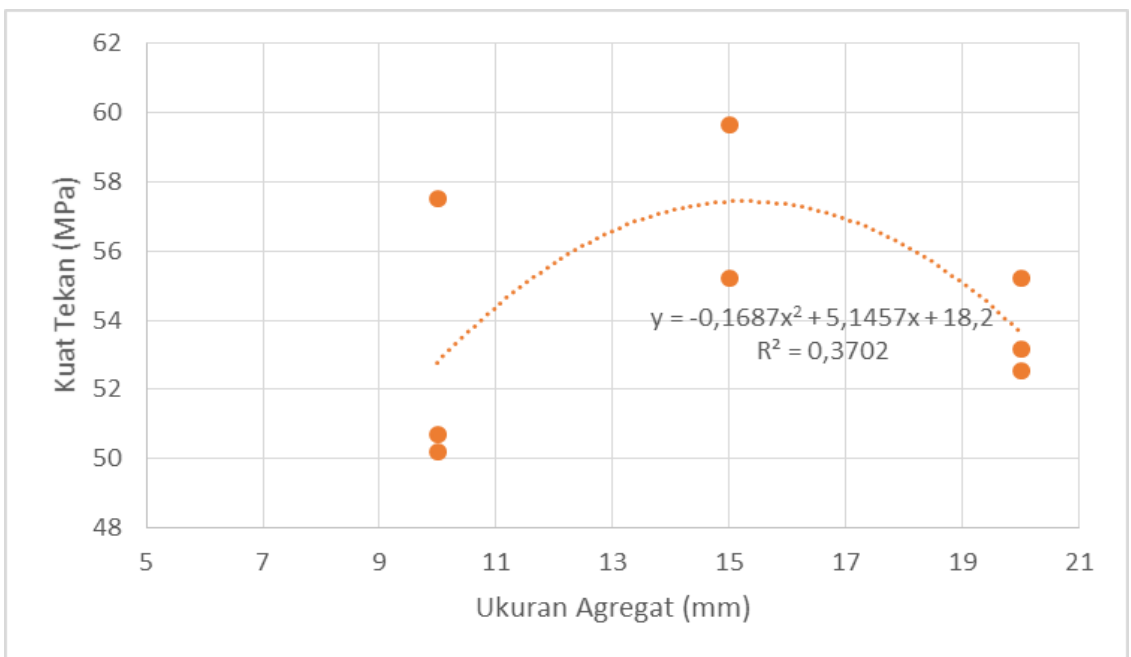

Gambar 5. Hubungan ukuran agregat dengan kuat tekan

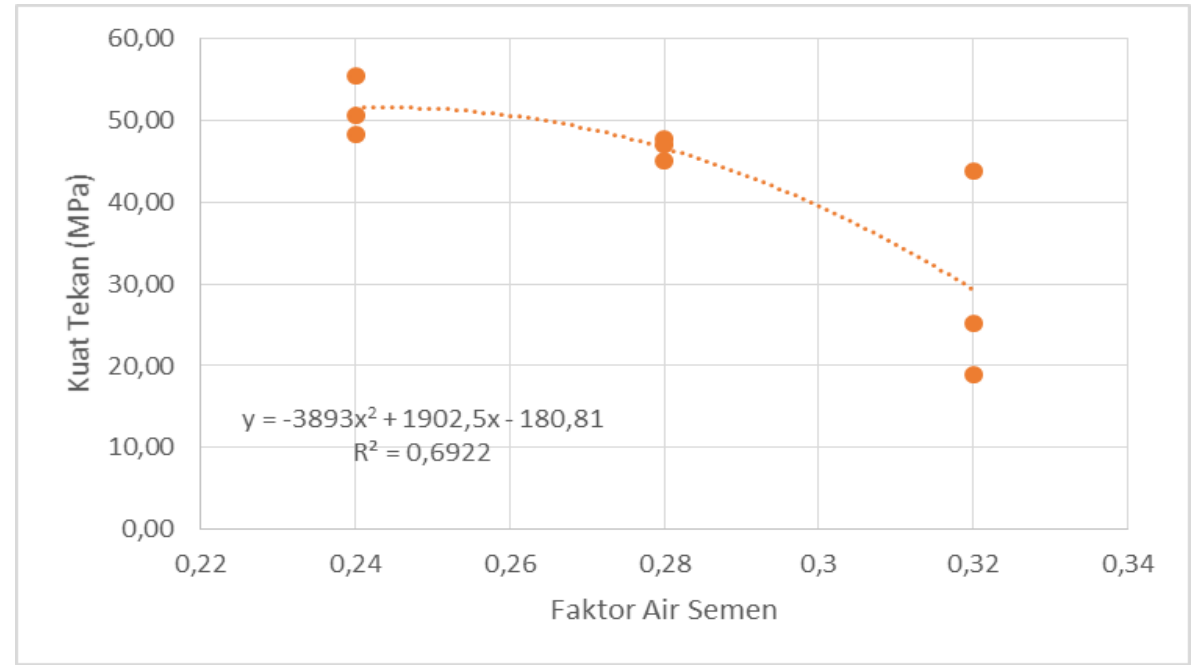

Gambar 6. Hubungan faktor air semen dengan kuat tekan 


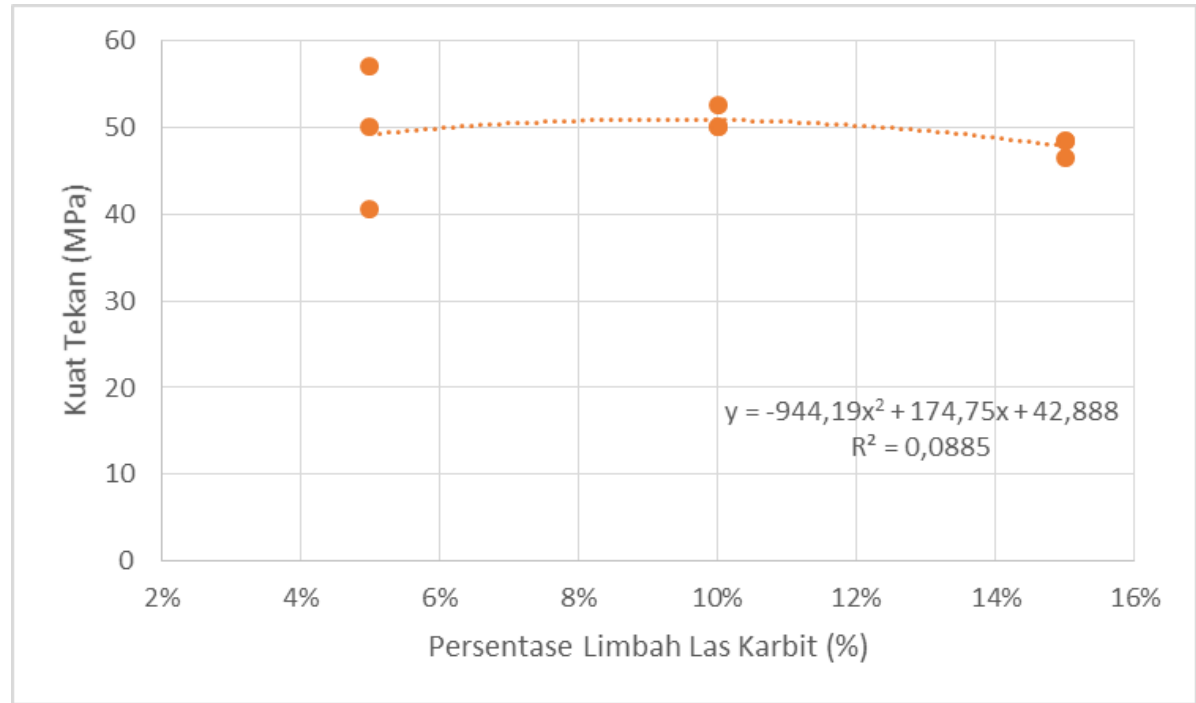

Gambar 7. Hubungan persentase limbah las karbit dengan kuat tekan

Tabel 6. Hasil uji kuat tekan beton

\begin{tabular}{cccc}
\hline Benda & \multicolumn{3}{c}{ Hasil Kuat Tekan Rata-Rata } \\
(MPa) & \\
Uji & Umur 7 & Umur 14 & Umur 28 \\
& Hari & Hari & Hari \\
\hline BT-1 & 42.05 & 47.25 & 52.79 \\
BT-2 & 35.52 & 52.95 & 57.44 \\
BT-3 & 43.92 & 46.63 & 53.65 \\
BT-4 & 38.06 & 44.11 & 51.54 \\
BT-5 & 17.77 & 29.25 & 29.33 \\
BT-6 & 43.45 & 48.42 & 49.26 \\
BT-7 & 42.60 & 41.34 & 47.86 \\
\hline
\end{tabular}

Berdasarkan seluruh data yang diperoleh dapat juga di analisispengaruh ukuran agregat maksimum terhadap kuat tekan, pengaruh faktor air semen optimum terhadap kuat tekan serta pengaruh kadar limbah las karbit terhadap kuat tekan.

Hasil pengaruh ini masing-masing dapat dilihat pada Gambar 5, Gambar 6 dan Gambar 7.

Pada Gambar 5 menunjukkan hubungan ukuran maksimum agregat kasar dengan kuat tekan beton. Dapat disimpulkan bahwa ukuran agregat kasar yang paling optimum dalam pembuatan beton mutu tinggi yaitu dengan ukuran agregat maksimum $15 \mathrm{~mm}$.

Pada Gambar 6 menunjukkan hubungan antara faktor air semen dengan kuat tekan beton dimana dapat ditarik kesimpulan bahwa semakin kecil faktor air semen dapat membuat beton semakin tinggi kuat tekannya.

Pada Gambar 7 menunjukkan hubungan persentase limbah las karbit dengan kuat tekan beton dimana diperoleh kadar optimum limbah las karbit yang cocok digunakan dalam permbuatan beton mutu tinggi adalah sebesar $10 \%$.

\section{KESIMPULAN}

Berdasarkan hasil dan pembahasan di atas, dapat ditarik kesimpulan diantaranya sebagai berikut:

a. Kuat tekan tertinggi yang diperoleh pada umur 28 hari sebesar 57.44 MPa dengan campuran faktor air semen 0.28, ukuran butir maksimum agregat kasar $15 \mathrm{~mm}$ dan persentase limbah las karbit $10 \%$.

b. Berdaraskan analisis menggunakan regresi polinomial, diperoleh ukuran terbaik agregat kasar terbaik dalam pembuatan beton mutu tinggi adalah $15 \mathrm{~mm}$ dengan faktor air semen 0.24 dan pemanfaatan limbah las karbit sebesar $10 \%$.

c. Hanya benda uji BT-5 yang memperoleh kuat tekan di bawah $40 \mathrm{MPa}$ sehingga semua campuran selain BT-5 dapat dikategorikan beton dengan mutu yang tinggi.

\section{UCAPAN TERIMA KASIH}

Penulis ingin mengucapkan terima kasih kepada saudara Arich Villano Gian Pratama Suwardih, Ardiandika Saputra dan Romi Irawan yang telah banyak membantu dalam proses penelitian ini. Selain itu, penulis ingin mengucapkan terima kasih kepada staff laboratorium teknologi bahan konstruksi 
Jurusan Teknik Sipil, Fakultas Teknik, Universitas Muhammadiyah Yogyakarta.

\section{DAFTAR PUSTAKA}

[1] Badan Standarisasi Nasional. 2000. Standar Nasional Indonesia 03-6468-2000 (Tata cara perencanaan campuran beton berkekuatan tinggi dengan semen portland dan abu terbang). Departemen Pekerjaan Umum. Jakarta.

[2] Ervianto, M. Saleh, F. Prayuda, H. Kuat Tekan Beton Mutu Tinggi Menggunakan Bahan Tambah Abu Terbang (Fly Ash) dan Zat Adiktif (Bestmittel). Jurnal Sinergi. Vol.20 No.3. pp 199-206 (2016).

[3] Nugraha, Y. Prayuda, H. Saleh, F. Pengaruh Variasi Bahan Tambah Abu Sekam dan Zat Adiktif Bestmittel 0.5\% Terhadap Kuat Tekan Beton Mutu Tinggi. Jurnal Ilmiah Semesta Teknika. Vol.20 No.2. pp 116-124 (2017).

[4] Fladr , J. Bily, P. Specimen Size Effect on Compressive and Flexural Strength of High St rength Fibre-Reinforced Concrete Containing Coarse Aggregare. Composite Part B. Vol 138 . pp 77-86 (2018).

[5] El-Din, H, K, S. Eisa, A, S. Aziz. B, H., A. Ibrahim, A. Mechanical Performance of High Strength Concrete Made From High Volume of Metakaolin and Hybrid Fibers. Journal Construction and Building Materials. Vol 140. Pp 203-209 (2017).

[6] McGinnis, M, J. Davis, M. Rosa, A, D, L.
Weldon, B, D. Kurama, Y,C. Strength and Stiffness of Concrete with Recycled Concrete Aggregates. Journal Construction and Builsing Materials. Vol 154. Pp 258-269 (2017).

[7] Laskar, S, M. Talukdar, S. Preparation and Tests for Workability, Compressive and Bond Strength of Ultra-Fine Slag Based Geopolymer as Concrete Reapiring Agent. Journal Construction and Building Materials. Vol 154. Pp 175-190 (2017).

[8] Thomas, R, J. Peerthamparan, S. Stepwise Regression Modeling for Compressive Strength of Alkali-Activated Concrete. Journal Construction and Building Materials. Vol 141. Pp 315-324 (2017).

[9] Behnood, A. Behnood, V. Gharehveran, M, M. Alyamac, K, E. Prediction of The Compressive Strength of Normal and High Performance Concretes using M5P Nodel Tree algorithm. Journal Constructuion and Building Materials. Vol 142. Pp 199-207 (20170.

[10] Jin, N, J. Seung, I. Choi, Y, S. Yeon, J. Prediction of Early Age Compressive /strength of Epoxy Resin Concrete Using The Maturity Method. Jounral Construction and Building Materials. Vol 152. Pp 990-998 (2017).

[11] American Concrete Institute. 2008. 211.4R-08 (Guide For Selecting Proportions For High Strength Concrete Using Portland Cement and Other Cementitious Materials). ACI Comette 211. USA. 